\title{
KAWASAKİ HASTALIĞI VE DENTAL YAKLAŞIMLAR
}

\section{Kawasaki Disease and Dental Approaches}

\author{
Merve CANDAN ${ }^{1}$ (1) Irem IPEK ${ }^{2}$ (1) Murat ÜNAL ${ }^{3}$ \\ ${ }^{1,2,3}$ Cumhuriyet Üniversitesi, Diş Hekimliği Fakültesi, Sivas
}

\begin{abstract}
Geliş Tarihi / Received: 15.06.2020
Kabul Tarihi / Accepted: 24.09.2020

Yayım Tarihi / Published: 30.11 .2020

\section{ÖZ}

Mukokutanöz lenf nodu sendromu olarak da bilinen Kawasaki hastalığı (KH), kendini sınırlayan orta çaplı musküler arter vasküliti olup, gelişmiş ülkelerdeki çocuklarda edinilmiş kalp hastalığının en yaygın nedenidir. Hastalık çoğunlukla 5 yaşın altındaki çocukları etkiler. KH' nin tedavisinde intravenöz immünoglobulin (IVIG) ile birlikte asetil salisilik asit (ASA) kullanımı standart tedavi olarak kabul edilir. Yaşam boyu tromboz, koroner stenoz, miyokard enfarktüsü, kalsifikasyonlar, dev koroner arter anevrizması rüptürü ve ani ölüm gibi komplikasyonları olan bu çocukluk çağı hastalığının, erken tanı ve tedavisi çok önemlidir. KH' de oral bulguların sıkça görülmesi, özellikle pediatrik diş hekimlerinin $\mathrm{KH}$ tanısında rol alabileceğini gösterir. Ayrıca $\mathrm{KH}$ bulguları, tedavisi ve komplikasyonları dental tedavi prosedürleri sırasında diş hekimlerinin hastalara yaklaşımlarını etkiler. Bu derlemenin amacı, tüm dünyayı etkileyen COVID-19 pandemisi döneminde yeniden gündeme gelen $\mathrm{KH}$ hakkındaki güncel bilgileri paylaşmak ve bu hastaların dental tedavileri sırasında diş hekimlerinin yaklaşımlarına yol gösterici olmaktır.
\end{abstract}

Anahtar kelimeler: Çocukluk Hastalıkları, Dental Yaklaşımlar, Kawasaki Hastalığı

\section{ABSTRACT}

Kawasaki disease (KD), also known as mucocutaneous lymph node syndrome, is a self-limiting medium-sized muscular artery vasculitis and is the most common cause of acquired heart disease in children in developed countries. The disease mostly affects children under 5 years old. In the treatment of KD, use of intravenous immunoglobulin (IVIG) together with acetylsalicylic acid (ASA) is accepted as the standard treatment. Early diagnosis and treatment is very important in this childhood disease, which has life-long complications such as thrombosis, coronary stenosis, myocardial infarction, calcifications, the rupture of giant coronary artery aneurysm and sudden death. The frequent occurrence of oral symptoms in KD indicates that pediatric dentists may play a role in the diagnosis of $\mathrm{KD}$. Also, the symptoms, treatment and complications of $\mathrm{KD}$ affect the approach of dentists to patients during dental treatment procedures. The aim of this review is to share current information about KD which has come to the agenda during the COVID-19 pandemic that affected the world, and to guide the dentist's approaches during dental treatment of these patients.

Keywords: Childhood Diseases, Dental Approaches, Kawasaki Disease 


\section{GíRiş}

Mukokutanöz lenf nodu sendromu olarak da bilinen Kawasaki hastalığı (KH), kendini sınırlayan orta çaplı musküler arter vaskülitidir ve özellikle koroner arterleri tutar (Modesti ve Plewa, 2020). KH gelişmiş ülkelerdeki çocuklarda edinilmiş kalp hastalığının en yaygın nedenidir ve ağırlıklı olarak 5 yaşın altındaki çocukları etkiler (McCrindle vd., 2017). Hastalığın tanı kriterleri zaman içinde değişmekle birlikte, en son 2017 yılında Amerikan Kalp Derneği (AKD) tarafından bildirilmiştir. Buna rağmen, hastalığın eksik veya atipik formları nedeniyle, özellikle bebeklerde ve küçük çocuklarda tanı zorlayıcı olabilir (Singh, Jindal, ve Pilania, 2018). Klinik bulgularına ateş, ekstremite değişiklikleri, deride döküntü, konjunktivit, oral değişiklikler, servikal lenfadenopati örnek verilebilir. KH' nin standart tedavisi, intravenöz immünoglobulin (IVIG) ile birlikte asetil salisilik asit (ASA) kullanımıdır. Bununla birlikte hastalığa sebep olan patojenik faktörler hala açıklığa kavuşturulamamıştır (Tang vd., 2020).

$\mathrm{KH}$, yaşam boyu potansiyel komplikasyonları olan yaygın bir çocukluk hastalığıdır. KH' den etkilenen tüm çocuklarda, koroner arter lezyonlarının gelişip gelişmediğine bakılmaksızın, endotel hasarının ve vasküler reaktivitenin bozulmasının uzun vadeli etkileri endişe vericidir (Yeung, 2005). Bu nedenle, KH' nin erken tanı ve tedavisi çok önemlidir, ayrıca KH' nin prevalansındaki artış, kardiyovasküler komplikasyonlara sahip daha fazla yetişkin popülasyonuna yol açmaktadır (Denby, Clark, ve Markham, 2017). COVID-19 teşhisi konan pediatrik hastaların klinik seyrinin daha fazla açıklanması, özellikle KH ile potansiyel ilişkisinin olup olmadığının açıklığa kavuşması için önemlidir (Jones vd., 2020).

Bu derlemenin amacı, tüm dünyayı etkileyen COVID-19 pandemisi döneminde yeniden gündeme gelen $\mathrm{KH}$ hakkındaki güncel bilgileri paylaşmak ve bu hastaların dental tedavileri sırasında diş hekimlerinin yaklaşımlarına yol gösterici olmaktır.

\section{KH' NIN EPIDEMIYOLOJISI}

Asyalı ve Pasifik Adalı çocuklarda, özellikle Japon çocuklarda, artmış KH insidansı görülmektedir ve beyaz çocuk insidansı bu etnik gruplara oranla daha düşüktür (Holman vd., 2010). Hastalığa dair birçok genetik analiz yapılmasına rağmen, şimdiye kadar hastalığın ortaya çıkması için kesin bir genetik zemin bulunamamıştır (Nakamura, 2018). KH ağırlıklı olarak 5 yaşın altındaki çocukları etkiler, fakat bu durum diğer yaş gruplarını etkilemeyeceği anlamına gelmez. Kuzey Amerika' da tahmin edilen insidans, 5 yaş altı çocuklarda 25/ 100.000 vakadır ve hastalık özellikle kış ve ilkbaharın başlarında görülür (McCrindle vd., 
2017). Hastalık öyküsü olan ebeveynlere sahip çocuklar $\mathrm{KH}$ açısından yüksek risk taşımaktadır (Nakamura, 2018). Türkiye' deki KH prevelansı tam olarak bilinmemekte olup, ülkemizde yapılan bir araştırmada $\mathrm{KH}^{\prime}$ nin çocukluk çağı vaskülitlerinin \% 9 'unu oluşturduğu bildirilmiştir (Özen vd.,2007)

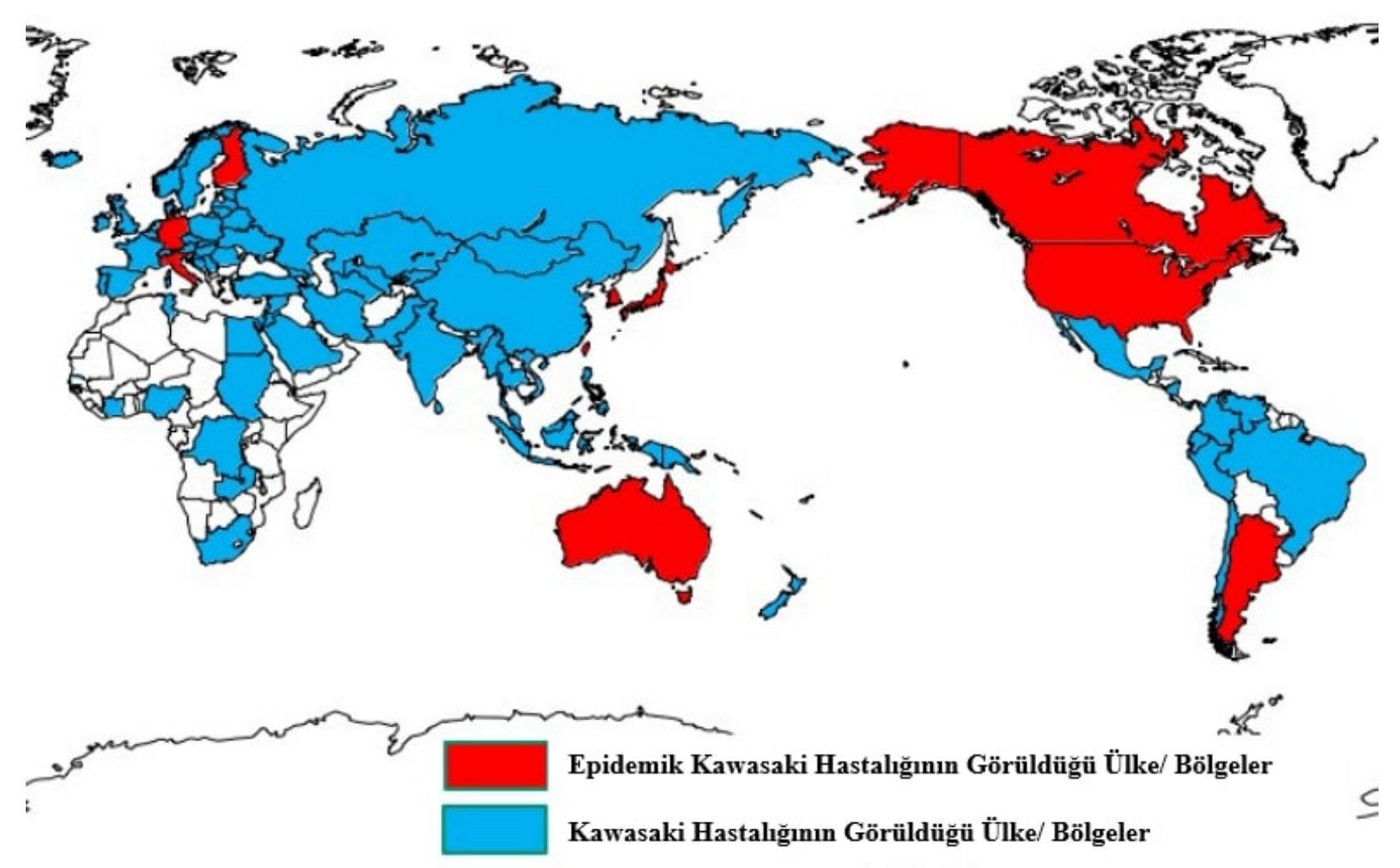

Şekil 1: Dünya Genelinde KH (Nakamura, 2018) (Şekil, Nakamura Y. Kawasaki disease: epidemiology and the lessons from it. Int J Rheum Dis. 2018;21(1):16-19 makalesinden alınıp, Türkçeye çevrilmiştir. Telif hakk1 International Journal of Rheumatic Diseases dergisine aittir, 2018)

\section{KH ETIYOLOJISİ - PATOGENEZI}

Yaklaşık 40 yıllık kapsamlı araştırmalara rağmen, $\mathrm{KH}^{\prime}$ nin nedenleri kesin olarak bilinmemektedir (McCrindle vd., 2017). KH’ nin öncelikle kış-bahar mevsimselliği ve salgın dönemlerindeki dalga benzeri yayılımı, bulaşıcı bir tetikleyiciyi destekler, buna rağmen bugüne kadar KH ile spesifik bir patojen ilişkilendirilememiş̧ir (Rowley ve Shulman, 2018). $\mathrm{KH}^{\prime}$ nin mevsimselliği, viral (muhtemelen solunum yolu kaynaklı) etiyolojiyi düşündürmektedir (Holman vd., 2010).

Epidemiyolojik veriler, $\mathrm{KH}$ ' nin etiyopatogenezinde yer alan bazı genetik varyantlara kanıt olarak gösterilebilir (Kumrah, Vignesh, Rawat, ve Singh, 2020). 2018 yılında yapıllan bir çalışma, $\mathrm{KH}$ patogenezinin, genellikle asemptomatik enfeksiyona neden olan bir RNA virüsü içerdiğini, ancak genetik olarak yatkın çocukların bir alt kümesinde $\mathrm{KH}$ oluştuğunu varsaymaktadır (Rowley ve Shulman, 2018). KH' nin ortaya çıkması için kesin bir genetik 
zemin bulunamamasına rağmen (Nakamura, 2018), T hücresi aktivasyonuna özgü yatkınlığa sebep olan $\mathrm{Ca}^{+2}$ / NFAT sinyalizasyonundaki artış (ITPKC, ORAI1, STIM1 genleri), doğal bağışıklık aktivasyonundaki artış (PELI1, COPB2 genleri), düzensiz B hücre sinyali (BLK, CD40, FCGR2B genleri) veya enflamatuar hücrelerin (CASP3 geni) kusurlu apopitozu, belirli popülasyonda KH ve IVIG yanıtı insidansındaki artışı açıklayabilir (Kumrah vd., 2020).

KH' nin, birkaç farklı mikrobiyolojik ajanın herhangi biri tarafindan tetiklenen bir immünolojik yanıttan kaynaklanması da mümkündür (Newburger vd., 2004). Adaptif bağışıklığın iki kolunun aktivasyonu, KH' nin akut fazı sırasında meydana gelir ve kanıtlar, T hücrelerinin ve B hücrelerinin aktivasyonunu ve proenflamatuar sitokin üretimini önemli ölçüde artırdığını göstermektedir (Yeung, 2005). KH' deki bağışıklık yanıtı, poliklonalden (tipik olarak süper antijen kaynaklı tepkilerde görüldüğü gibi) ziyade oligoklonaldır (antijen güdümlüdür, yani geleneksel bir antijen benzeri tepki) ve immünoglobulin A (IgA) yanıtta merkezi bir rol oynar (Rowley, Shulman, Spike, Mask, ve Baker, 2001). Ayrıca Vasküler endotelyal büyüme faktörü (VEGF) (Ohno vd., 2002), Monosit kemotaktik ve aktive edici faktör (MCAF veya MCP-1) (Asano ve Ogawa, 2000), Tümör nekroz faktörü- $\alpha$ (TNF- $\alpha$ ) (Furukawa, Matsubara, Umezawa, Okumura, ve Yabuta, 1994) ve çeşitli interlökinlerin de vaskülitik süreçte önemli roller oynadığı düşünülmektedir.

Tekrarlayan $\mathrm{KH}$, enflamatuar belirteçlerin seviyelerinin tamamen normalleşmesinin ardından, KH' nin ilk döneminden en az 3 ay sonra ve genellikle 2 yıl içinde başlayan, KH kriterlerini karşılayan yeni bir hastalık olarak tanımlanır. KH’ nin nüksü oldukça nadirdir. Nüks için risk faktörlerine örnek olarak, erkek cinsiyete sahip olma, üç yaşından küçük olma ve ilk atakta ilk IVIG tedavisine direnç verilebilir (Sudo ve Nakamura, 2017).

$\mathrm{KH}$ ilaçlara veya toksinlere (böcek ilaçları, kimyasallar ve ağır metaller gibi çevresel kirleticiler) maruziyet ile ilişkilendirilemese de, akrodini (cıva aşırı duyarlılığı) ile arasındaki klinik benzerlikler dikkat çekicidir (Newburger vd., 2004). KH’ nin etiyolojisi - patogenezi alanında yapılacak ileri düzeydeki kanıta dayalı çalışmalara ihtiyaç olduğu açıktır. Hastalığın etiyolojisinin tanımlanması, hastalıkla ilgili en önemli araştırma hedefidir. Çünkü bu bilgi ile bir teşhis testi geliştirilebilir, tedavi iyileştirilebilir veya hastalığın önlenmesi mümkün hale gelebilir (Rowley ve Shulman, 2018).

\section{KH' NINN BULGULARI}

\section{Klinik Bulgular}

KH tanısı AKD tarafından verilen klinik kriterlere dayanmaktadır (McCrindle vd., 2017) (Bakınız Tablo 1). KH' nin bulguları 5 günden fazladır süren ateş ve avuç içi 
polimorföz eritem, el ve ayak ödemi, ekstremite değişiklikleri, mukozadaki değişiklikler, kırmızı dudaklar, çilek dil, pürülan olmayan bilateral konjunktivit ve servikal lenfadenopati gibi klinik bulguların 4 veya daha fazlasının bir arada olmasını içerir (Kumrah vd., 2020; Newburger vd., 2004; Yeung, 2005).

Tablo 1. KH’ nin Klinik Bulguları (McCrindle vd., 2017; Saguil vd., 2015)

\begin{tabular}{|c|c|c|}
\hline Klinik Bulgular & Açıklamalar & Dışlanan durumlar \\
\hline Ateş & $\begin{array}{ll}\checkmark & \text { Tipik olarak azalıp-yükselen tarzda } \\
\checkmark & \text { Yüksek ateş }\left(>39-40^{\circ} \mathrm{C}\right)\end{array}$ & \\
\hline $\begin{array}{c}\text { Ekstremite } \\
\text { Değişiklikleri }\end{array}$ & $\begin{array}{ll}\checkmark & \text { Avuç içi ve ayak tabanlarında eritem } \\
\checkmark & \text { Akut fazda el ve ayakların ağrılı katılaşması } \\
\checkmark & \text { Genellikle ateş başlangıcından sonraki 2-3. } \\
& \text { haftada el ve ayak parmakları periungual } \\
& \text { bölgede deskuamasyon (avuç içi ve ayak } \\
& \text { tabanları içerecek şekilde uzanabilir) } \\
\checkmark & \text { Ateş başladıktan 1 - 2 ay sonra tırnaklarda derin } \\
\text { enine oluklar (Beau çizgileri) }\end{array}$ & \\
\hline Deride Döküntü & $\begin{array}{ll}\checkmark & \text { Eritematöz döküntü (genellikle ateş başladıktan } \\
& \text { sonraki } 5 \text { gün içinde) } \\
\checkmark & \text { En sık makülopapüler tipte döküntüler } \\
\checkmark & \text { Döküntü genellikle geniştir, özellikle gövde ve } \\
& \text { ekstremiteleri içerir. } \\
\checkmark & \text { Diffüz eritem - eritema multiforme benzeri } \\
\checkmark & \text { Perineal bölgede belirgin deskuamasyon ve } \\
\checkmark & \text { karın üzerinde skarlatiniform erüpsiyon }\end{array}$ & $\begin{array}{c}\text { Büllöz, veziküler ve } \\
\text { peteşiyal döküntüler KH ile } \\
\text { uyumlu değildir. }\end{array}$ \\
\hline Konjunktivit & 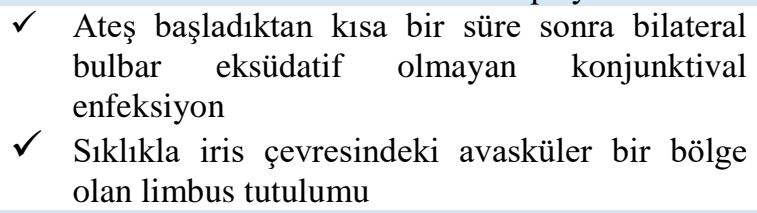 & \\
\hline $\begin{array}{l}\text { Oral Bölgedeki } \\
\text { Değişiklikler }\end{array}$ & 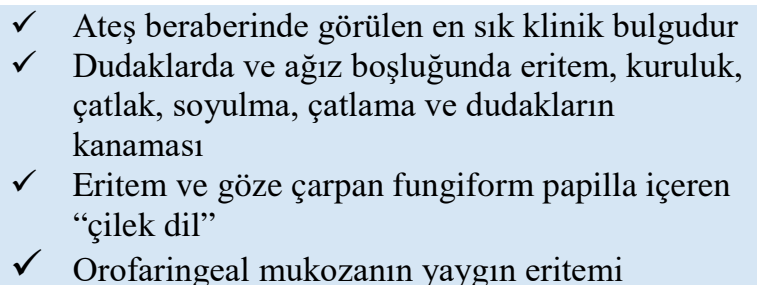 & $\begin{array}{c}\text { Oral ülserler ve faringeal } \\
\text { eksüdalar KH ile uyumlu } \\
\text { değildir. }\end{array}$ \\
\hline $\begin{array}{c}\text { Servikal } \\
\text { Lenfadenopati }\end{array}$ & $\begin{array}{ll}\checkmark & \text { KH’nin temel klinik özelliklerinden en az } \\
\text { yaygın olanı } \\
\checkmark \quad \begin{array}{l}\text { Lenf nodu büyümesi genellikle tek taraflı, } \geq 1.5 \\
\text { cm çapında ve ön servikal üçgenle sınırlı }\end{array} \\
\checkmark \quad \text { Çoklu lenf düğümü büyümesi görülebilir. } \\
\text { Retrofaringeal ödem - flegmon yaygın }\end{array}$ & \\
\hline
\end{tabular}

Diğer klinik bulgular ise (McCrindle vd., 2017); miyokardit, perikardit, kapak yetersizliği, koroner arter anomalileri, orta çaplı arterlerin anevrizmaları, periferik gangren, aort kökü büyümesi, akciğer radyografisinde peribronşiyal ve interstisyel infiltratlar, pulmoner nodüller, artrit, artralji, ishal, kusma, karın ağrısı, hepatit, sarılık, safra kesesi hidropları, pankreatit, aşırı irritabilite, aseptik menenjit (beyin omurilik sıvısının pleositozu), fasial paralizi, sensorinöral işitme kaybı, üretrit / etit, hidrosel, kasıkta deskuamatif döküntü, retrofaringeal flegmon, anterior üveit ve BCG aşılama yerinde eritem - sertleşmedir. 


\section{Laboratuvar Bulguları}

KH' nin akut evresinde, tipik olarak nötrofil baskınlığg ile normal veya yüksek beyaz kan hücresi sayısı, C-reaktif protein (CRP) ve eritrosit sedimantasyon hızı (ESR) dahil olmak üzere yüksek seviyelerde akut faz reaktanları gözlenir (McCrindle vd., 2017; Newburger vd., 2004; Saguil, Fargo, ve Grogan, 2015). KH' nin akut fazında abartılı bir doğal bağışıklık tepkisi bulunur ve düşük serum $\mathrm{Na}^{+}$ve albümin değerleri, yüksek serum karaciğer enzimleri ve steril piyuri gözlenebilir, trombositoz genellikle ilk haftanın sonunda görülür (Kumrah vd., 2020; Saguil vd., 2015).

\section{Ayricı Tanısı}

Ayrıcı tanısı, kızamık ve diğer viral enfeksiyonlar (örn; adenovirüs, enterovirüs) stafilokoksik haşlanmış deri sendromu, streptokokal kızıl ateşi, Stevens Johnson sendromunu da içeren aşırı duyarlılık reaksiyonları, toksik şok sendromu ve jüvenil idiyopatik artrit ile yapılmalıdır (Saguil vd., 2015).

\section{KH' NIN TEDAVISİ, PROGNOZU VE KOMPLIKKASYONLARI}

KH hakkında artan doktor farkındalığı, hastalığın erken teşhisini ve klasik semptomlarla başvuran çocukların tedavisini kolaylaştırsa da, hastalığın atipik formları nedeniyle, özellikle bebeklerde ve küçük çocuklarda tanı zorlayıcı olabilir (Singh vd., 2018). Bu hastalarda gerçekleşen gecikmiş tanı ve tedavi koroner arter anomalileri riskini artırır (Sosa, Brower, ve Divanovic, 2019). Hızlı tanı ve IVIG ile tedavi, koroner arter anevrizmalarını (KAA) önler (McCrindle vd., 2017).

Koroner arter anormalliklerini önlemek için, ateşin başlamasından sonraki 10 gün içinde 2 doz / kg IVIG ve orta - yüksek doz ASA verilmelidir (McCrindle vd., 2017; Sosa vd., 2019). IVIG tedavisi pahalı olmakla birlikte, nispeten güvenlidir ve fayda tipik olarak risklerden ağır basar. IVIG, havuzlanmış donör plazmasının biyolojik bir ürünü olduğundan, yan etkiler ürünler arasında farklılık gösterir (Sosa vd., 2019). Kızamık, kabakulak ve suçiçeği aşıları, yüksek doz IVIG aldıktan sonra 11 ay ertelenmelidir (Red Book, 30th Edition (2015) | AAP EBooks, t.y.).

ASA özellikle hasarlı damarlarda tromboz riski göz önüne alındığında, antienflamatuar ve antiplatelet aktivitesi için kullanılır. Tanı konulduktan sonra 4' e bölünmüş dozda günlük 80 - $100 \mathrm{mg} / \mathrm{kg}$ ' lik dozda uygulanır. Yüksek doz ASA tedavisi genellikle 48-72 saat, hastanın ateş bulgusu olmayana kadar, uygulanır. Daha sonra düşük doz ASA tedavisi (tek bir günlük dozda 3-5 mg/kg/gün), hastalığın başlamasından 6-8 hafta sonra takip 
ekokardiyogramına kadar verilir veya koroner arter anormallikleri olan çocuklar için süresiz olarak devam eder (Red Book, 30th Edition (2015) | AAP EBooks, t.y.). Çocukluk çağında, yüksek doz ASA kullanımı ile ortaya çıkan en önemli potansiyel komplikasyon, Reye sendromudur (Sosa vd., 2019). ASA tedavisi sırasında canlı-atenüe aşılardan kaçınılmalıdır. Hasta çocuk ve 6 aydan büyük tüm hane halkı mevsimsel önerilere göre, influenza aşısı yaptırmalıdır. KH olan bir çocuk aspirin kullanımına devam ediyorsa, inaktive influenza aşısı kullanılmalıdır (Red Book, 30th Edition (2015) | AAP EBooks, t.y.).

\section{Reye Sendromu}

ASA, akut koroner sendromlu hastalarda antitrombosit tedavinin temel taşıdır ve birçok sağlık kuruluşu tarafından tavsiye edilir (Magrum ve Pickworth, 2020). Reye sendromu, yağl1 karaciğer yetmezliği ile birlikte akut enflamatuar olmayan ensefalopati olarak tanımlanan nadir ve potansiyel olarak ölümcül bir pediatrik hastalıktır. Genellikle viral bir hastalıktan iyileşmeyi takip eden günlerde, uygulanan ASA tedavisi sebebiyle başlar. Bununla birlikte konjenital metabolizma hataları (özellikle yağ asidi metabolizması), ilaç reaksiyonları veya toksinler de Reye sendromunun gelişmesine neden olabilir. Çocuklarda tipik olarak kusma ve konfüzyon ile kendini gösterir, hızlı bir şekilde koma ve ölüme sebep olabilir (Chapman ve Arnold, 2020). Çocukluk çağında Reye sendromu öyküsü olan bir yetişkinde aspirin ile tekrar maruziyet güvenli olabilir (Magrum ve Pickworth, 2020).

Genel olarak, antiplatelet etkileri nedeniyle ASA alan, koroner anevrizması olan çocuklarda, ibuprofen kullanımından kaçınılmalıdır. Çünkü ibuprofen ASA tarafından indüklenen trombosit inhibisyonunu antagonize eder (Red Book, 30th Edition (2015) | AAP EBooks, t.y.).

Kortikosteroid kullanımı sistemik vaskülitte temel tedavi yöntemi olmasına rağmen, KH' de kullanımları sınırlıdır (Yeung, 2005). Ayrıca IVIG' ye dirençli hastalarda hastalığın tedavisinde yardımcı ajanların ve stratejilerin kullanımı tartışmalıdır. IVIG' ye direnç varsa, ikinci bir IVIG dozu önerilebilir ve bazı durumlarda kortikosteroidler, infliksimab, sitotoksik ajanlar, immünomodülatörler ve plazma değişimi de dikkate alınabilir (Sosa vd., 2019).

KH takibinde miyokardiyal disfonksiyona bağlı gelişen ejeksiyon fraksiyon düşüşünü ve KAA' ların gelişimini değerlendirmek adına ekokardiyogram önemlidir. Zamanında tedavi alamayan KH' li çocukların \% 25' inde KAA ortaya çıkabilir (McCrindle vd., 2017). KH' nin komplikasyonlarına, tromboz, koroner stenoz, miyokard enfarktüsü, kalsifikasyonlar, dev KAA rüptürü ve ani ölüm örnek verilebilir. Ölümün ana nedeni, anevrizma trombozu veya 
stenotik lezyona bağlı miyokard enfarktüsüdür. Ayrıca KAA rüptürü, KH için çok nadir olsa da ölümcül bir komplikasyondur ( Wei, Zhao, Liu, Niu, ve Li, 2016).

\section{KH OLAN HASTALARDA DİŞ HEKIMI YAKLAŞIMI}

$\mathrm{Bu}$ hastaların dental tedaviler öncesi, KH tedavisi sırasında kullandıkları antitrombolitik ilaçların ve hastalığın meydana getirdiği kardiyovasküler komplikasyonların antibiyotik profilaksisi açısından pediatrik kardiyolojiye konsülte edilmesi önemlidir.

Enfektif endokardit (EE), kalp kapakçığında bakteriyel vejetasyonların oluştuğu sistemik bir septik hastalık olarak kabul edilir. EE nadiren görülse de, sıklıkla bir kalp hastalığı öyküsü olan hastalarda gelişir ve uygun tedaviler yapılmaz ya da gerekli önlemler alınmazsa, hastalar çeşitli komplikasyonlar sebebiyle kaybedilebilirler (Cahill vd., 2017). Stafilakokus aureus, koagülaz negatif stafilokoklar, enterokoklar, viridans grubu streptokoklar, streptokokus bovis, fungaller ve HACEK grubu bakteriler ( Hemofilus türleri, Agregatibakter türleri, Kardiobakterium hominis, Eikenella corrodens ve Kingella türleri ) EE etkeni olabilirler (Selton-Suty vd., 2012). Etiyolojisinde birçok mikroorganizma yer alsa da, Stafilokokus aureus ve viridans grubu streptokoklar ana etiyolojik ajanlar olarak tanınırlar (Chambers vd., 2013; Toyoda vd., 2017).

Oral streptokoklar, oral yüzeylere ilk kolonize olan ve oral kavitedeki baskın mikroorganizmalardır. Ayrıca son zamanlarda EE, bakteriyemi, pürülan enfeksiyonlar, beyin kanaması, bağırsak iltihabı ve otoimmün hastalıklar gibi çeşitli sistemik hastalıkların patojenleri olarak dikkat çekmişlerdir (Yumoto vd., 2019). Geçici bakteriyemi, dişlerin ve periodontal dokuların manipülasyonu sırasında oldukça yaygındır ve dental prosedürlerden kaynaklanan bakteriyeminin rapor edilen oranları çeşitlilik göstermektedir (Bakınız Tablo 2). Dental prosedürlerin, çiğneme, diş fırçalama veya diş ipi kullanımı gibi rutin günlük aktiviteler sırasında oluşan geçici bakteriyemiden daha fazla bakteriyemiye sebep olup olmadığı bilinmemektedir (Wilson vd., 2007).

Tablo 2. Bakteriyemiye Sebep Olan Dental Prosedürler ve Oranları (Wilson vd., 2007)

\begin{tabular}{|c|c|}
\hline Dental prosedürler & Bakteriyemi oranı \\
\hline Diş Çekimi & $\% 10-\% 100$ \\
\hline Periodontal Cerrahi & $\% 36-\% 88$ \\
\hline Detertraj - küretaj işlemleri & $\% 8-\% 80$ \\
\hline Rubberdam / kama yerleştirilmesi & $\% 9-\% 32$ \\
\hline Endodontik prosedürler & \% 20 'e kadar \\
\hline \multicolumn{2}{|l|}{ Bireysel dental bakım prosedürleri } \\
\hline Diş firçalama ve diş ipi kullanımı & $\% 20-\% 68$ \\
\hline Kürdan kullanımı & $\% 20-\% 40$ \\
\hline Ağız duşu vb. cihazlar & $\% 7-\% 50$ \\
\hline Çiğneme sırasında & $\% 7-\% 51$ \\
\hline
\end{tabular}


$\mathrm{KH}$, dünya genelinde çocukluk çağında kazanılmış kalp hastalıklarına en sık neden olan hastalık olduğu için, $\mathrm{AKD}$ ' ye göre $\mathrm{EE}$ açısından risk taşıyan $\mathrm{KH}^{\prime}$ de kanamalı dental tedaviler öncesinde antibiyotik profilaksisi uygulanması gerekmektedir (Makino vd., 2015). Kanamaya sebep olabilecek dental tedaviler Tablo 3' te gösterilmiştir (SDCEPAnticoagulants-Quick-Reference-Guide.pdf, t.y.).

Her ne kadar dental prosedürler 3 ayrı grup altında değerlendirilmiş olsa da, bu durum kesin olmayıp operasyon öncesi dönemde, ilgili hastanın genel sağlık ve oral durumu göz önünde bulundurulmalıdır. KH' nin akut döneminde yüklenen yüksek doz ASA sebebiyle bu dönemde acil olmayan kanamalı dental prosedürler ertelenmelidir. Acil tedavi gerektiren durumlarda pediatrik kardiyolojiye konsültasyonu mutlaka gereklidir.

ASA, KH' nin tedavisinde uzun yıllardan beri kullanılmaktadır (McCrindle vd., 2017; Sosa vd., 2019). Kronik antiplatelet tedavisi altındaki bireylerin kanama için risk grubu olarak değerlendirilmesi sebebiyle, bu hastalara dental tedavi öncesi hekim konsültasyonu gereklidir (Ringel ve Maas, 2016). 2013 yllında yayınlanan bir derlemede, invaziv dental prosedürlerden önce antiplatelet tedaviyi değiştirme veya bırakmaya gerek olmadığı ve nadiren gelişen postoperatif kanama durumunda lokal hemostatik önlemlerin etkili olduğu bildirilmiştir (Napeñas vd., 2013).

Tablo 3. Risk Gruplarına Göre Kanamalı Dental Prosedürler (SDCEP-Anticoagulants-Quick-ReferenceGuide.pdf, t.y.)

\section{Kanamaya neden olmayan dental prosedürler}

$\checkmark \quad$ Lokal anestezi

$\checkmark$ (İnfiltrasyon intraligamenter ,mental, rejyonel anestezi )

$\checkmark \quad$ Temel periodontal muayene

$\checkmark \quad$ Supragingival plak, kalkulus ve lekelerin temizlenmesi

$\checkmark \quad$ Supragingival marjinlere sahip direkt - indirekt restorasyonlar

$\checkmark \quad$ Ortograd endodontik prosedürler

$\checkmark \quad$ Ölçü alımı ve diğer protetik prosedürler

$\checkmark$ Ortodontik apareylerin uygulanması ve ayarlanması
Düșük kanama riski olan dental prosedürler

$\checkmark \quad$ İntraoral şişliklerin drenajı ve insizyonu

$\checkmark$ Basit çekimler

$\checkmark \quad$ (1-3, sınırlı yara yüzeyine sahip )

$\checkmark$ Detaylı tam periodontal muayene

$\checkmark \quad$ Kök yüzeyi düzleştirilmesi

$\checkmark$ Subgingival marjinlere sahip direkt ve indirekt restorasyonlar
Yüksek kanama riski olan dental prosedürler

\footnotetext{
$\checkmark$ Diş çekimi ( Travmatik, büyük yara yüzeyine sebep olan, veya aynı anda $>3$ adet )

$\checkmark \quad$ Flap kaldırma prosedürleri

$\checkmark \quad$ Elektif cerrahi ekstraksiyonlar

$\checkmark$ Periodontal cerrahi

$\checkmark \quad$ Protez öncesi cerrahi

$\checkmark$ Periradiküler cerrahi

$\checkmark$ Kuron uzatma

$\checkmark$ Dental implant cerrahisi

$\checkmark$ Gingival rekonstrüksiyon

$\checkmark$ Biyopsi
} 
Ayrıca KH' nin oral bulgularının diş hekimleri tarafından tanınması erken teşhiş açısından önemlidir. KH' de ateşin yanı sıra en sık görülen klinik bulgu \% 96,5 oranında dudak ve oral kavitedeki değişikliklerdir. Bu değişikliklere çatlak ve eritemli dudaklar, çilek dil ve orofaringeal mukozal yüzeylerin yaygın bir eritemi örnek verilebilir (Saguil vd., 2015). Bununla birlikte, bu kriterler düşük duyarlılığa ve özgüllüğe sahiptir ve bu nedenle, özellikle atipik KH vakaları için, tanının belirlenmesinde diğer klinik ve laboratuvar bulguları yardımcı olabilir (Sánchez-Manubens, Bou, ve Anton, 2014). KH’ li vakalarda siklıkla oral bulgularının görülmesi nedeniyle, hastalığın ön tanısında diş hekimlerinin hastalık bulguları hakkındaki farkındalığı önem kazanmaktadır. Nadiren de olsa KH' de fasiyal paralizi görülmesi, diğer klinik bulguların eşliğinde $\mathrm{KH}^{\prime}$ nin tanısında göz önünde bulundurulabilir (Zhang vd., 2019).

\section{SONUÇ}

$\mathrm{KH}$, yaşam boyu potansiyel komplikasyonları olan ve ani ölüm gelişebilen yaygın bir çocukluk hastalığıdır. Hastalığın tanısı, hastalığın formları sebebiyle bebeklerde ve küçük çocuklarda geç ve zor olabilir. Gecikmiş tanı ve tedavi koroner arter anomalileri riskini artırmaktadır. Hastalığın etiyolojisinin tanımlanması, hastalıkla ilgili en önemli araştırma hedefidir. Çünkü bu bilgi ile bir teşhis testi geliştirilebilir, tedavi iyileştirilebilir veya hastalığın önlenmesi mümkün hale gelebilir.

Hastalığın oral bulgularının da bulunması, özellikle pediatrik diş hekimlerinin KH hakkındaki farkındalığın artması gerektiğini ve tanıda yardımcı olabileceklerini düşündürür. $\mathrm{KH}$ seyrinin, tedavisinin ve komplikasyonlarının diş hekimleri tarafından bilinmesi dental prosedürler sırasında hastalara yaklaşımlarını belirler. Bu nedenle dental prosedürlerdeki yaklaşımlar şu şekilde olmalıdır.

- Hastaların geçmiş ve klinik anamnezi dikkatlice gözden geçirilmelidir ve KH' den şüphelenilen hastalar için pediatri ya da pediatrik kardiyoloji konsültasyonu istenmelidir.

- Bu hastalarda KH' ye bağlı kardiyovasküler bulgu ve komplikasyonlar bulunabileceğinden konsültasyon doğrultusunda, antibiyotik proflaksisi uygulanması gerekebilir.

- KH' nin akut fazında yüksek dozda uygulanan ASA' nın sebep olduğu antiplatelet etki sebebiyle, dental prosedürler sırasında kanama gerçekleşebilir. $\mathrm{Bu}$ sebeple akut fazda acil olmayan dental tedavilerin ertelenmesi gereklidir.

- Hastalığın idame döneminde düşük dozlardaki ASA kullanımı dikkate alınarak, akut dönemdeki acil dental prosedürler ve idame döneminde yapılacak olan düşük, orta veya 
yüksek kanama riskli dental prosedürler için pediatrik konsültasyon eşliğinde, kanama durdurucu önlemler alınmalıdır.

- İbubrofen, ASA tarafından indüklenen trombosit inhibisyonunu antagonize ettiği için, KH tedavisi gören hastalarda reçete edilmemelidir.

\section{KAYNAKLAR}

Asano, T., Ogawa, S. (2000). Expression of monocyte chemoattractant protein-1 in Kawasaki disease: The antiinflammatory effect of gamma globulin therapy. Scandinavian Journal of Immunology, 51(1), 98-103.

Cahill, T. J., Harrison, J. L., Jewell, P., Onakpoya, I., Chambers, J. B., Dayer, M., ... Prendergast, B. D. (2017). Antibiotic prophylaxis for infective endocarditis: A systematic review and meta-analysis. Heart (British Cardiac Society), 103(12), 937-944.

Chambers, S. T., Murdoch, D., Morris, A., Holland, D., Pappas, P., Almela, M., ...International Collaboration on Endocarditis Prospective Cohort Study Investigators. (2013). HACEK infective endocarditis: Characteristics and outcomes from a large, multi-national cohort. PloS One, 8(5), e63181.

Chapman, J., Arnold, J. K. (2020). Reye Syndrome. Içinde StatPearls. StatPearls Publishing. http://www.ncbi.nlm.nih.gov/books/NBK526101/

Denby, K. J., Clark, D. E., Markham, L. W. (2017). Management of Kawasaki disease in adults. Heart (British Cardiac Society), 103(22), 1760-1769.

Furukawa, S., Matsubara, T., Umezawa, Y., Okumura, K., Yabuta, K. (1994). Serum levels of p60 soluble tumor necrosis factor receptor during acute Kawasaki disease. The Journal of Pediatrics, 124(5 Pt 1), 721-725.

Holman, R. C., Christensen, K. Y., Belay, E. D., Steiner, C. A., Effler, P. V., Miyamura, J., ... Melish, M. (2010). Racial/ethnic differences in the incidence of Kawasaki syndrome among children in Hawaii. Hawaii Medical Journal, 69(8), 194-197.

Jones, V. G., Mills, M., Suarez, D., Hogan, C. A., Yeh, D., Bradley Segal, J., ... Mathew, R. (2020). COVID-19 and Kawasaki Disease: Novel Virus and Novel Case. Hospital Pediatrics,10(6), 537-540.

Kumrah, R., Vignesh, P., Rawat, A., Singh, S. (2020). Immunogenetics of Kawasaki disease. Clinical Reviews in Allergy \& Immunology, 59, 122-139.

Magrum, B. G., Pickworth, K. K. (2020). Aspirin rechallenge in an adult patient previously diagnosed with Reye syndrome. American Journal of Health-System Pharmacy: AJHP: Official Journal of the American Society of Health-System Pharmacists, 77(2), 123-127.

Makino, N., Nakamura, Y., Yashiro, M., Ae, R., Tsuboi, S., Aoyama, Y., ... Yanagawa, H. (2015). Descriptive epidemiology of Kawasaki disease in Japan, 2011-2012: From the results of the 22nd nationwide survey. Journal of Epidemiology, 25(3), 239-245.

McCrindle, B. W., Rowley, A. H., Newburger, J. W., Burns, J. C., Bolger, A. F., Gewitz, M., ... American Heart Association Rheumatic Fever, Endocarditis, and Kawasaki Disease Committee of the Council on Cardiovascular Disease in the Young; Council on Cardiovascular and Stroke Nursing; Council on Cardiovascular Surgery and Anesthesia; and Council on Epidemiology and Prevention. (2017). Diagnosis, Treatment, and Long-Term Management of Kawasaki Disease: A Scientific Statement for Health Professionals From the American Heart Association. Circulation, 135(17), e927-e999.

Modesti, A. M., Plewa, M. C. (2020). Kawasaki Disease. Içinde StatPearls. StatPearls Publishing. http://www.ncbi.nlm.nih.gov/books/NBK537163/

Nakamura, Y. (2018). Kawasaki disease: Epidemiology and the lessons from it. International Journal of Rheumatic Diseases, 21(1), 16-19. 
Napeñas, J. J., Oost, F. C. D., DeGroot, A., Loven, B., Hong, C. H. L., Brennan, M. T., ... van Diermen, D. E. (2013). Review of postoperative bleeding risk in dental patients on antiplatelet therapy. Oral Surgery, Oral Medicine, Oral Pathology and Oral Radiology, 115(4), 491-499.

Newburger, J. W., Takahashi, M., Gerber, M. A., Gewitz, M. H., Tani, L. Y., Burns, J. C., ... Taubert, K. A. (2004). Committee on Rheumatic Fever, Endocarditis, and Kawasaki Disease, Council on Cardiovascular Disease in the Young, American Heart Association. Diagnosis, treatment, and long-term management of Kawasaki disease: A statement for health professionals from the Committee on Rheumatic Fever, Endocarditis, and Kawasaki Disease, Council on Cardiovascular Disease in the Young, American Heart Association. Pediatrics, 114(6), 1708-1733.

Ohno, T., Yuge, T., Kariyazono, H., Igarashi, H., Joh-o, K., Kinugawa, N., ... Hara, T. (2002). Serum hepatocyte growth factor combined with vascular endothelial growth factor as a predictive indicator for the occurrence of coronary artery lesions in Kawasaki disease. European Journal of Pediatrics, 161(2), 105-111.

Özen, S., Bakkaloglu, A., Dusunsel, R., Soylemezoglu, O., Ozaltin, F., Poyrazoglu, H., ... Kural, N. (2007). Turkish Pediatric Vasculitis Study Group. Childhood vasculitides in Turkey: a nationwide survey. Clinical rheumatology, 26(2), 196-200.

Red Book, 30th Edition (2015) | AAP eBooks (30th Edition). (t.y.). 24 Temmuz 2020 tarihinde https://ebooks.aappublications.org/content/red-book-30th-edition-2015 adresinden erişildi.

Ringel, R., Maas, R. (2016). Dental procedures in patients treated with antiplatelet or oral anticoagulation therapy-An anonymous survey. Gerodontology, 33(4), 447-452.

Rowley, A. H., Shulman, S. T., Spike, B. T., Mask, C. A., Baker, S. C. (2001). Oligoclonal IgA response in the vascular wall in acute Kawasaki disease. Journal of Immunology (Baltimore, Md.: 1950), 166(2), 13341343.

Rowley, A. H., Shulman, S. T. (2018). The epidemiology and pathogenesis of Kawasaki Disease. Frontiers in Pediatrics, 6.

Saguil, A., Fargo, M. V., Grogan, S. P. (2015). Diagnosis and management of Kawasaki Disease. American Family Physician, 91(6), 365-371.

Sánchez-Manubens, J., Bou, R., Anton, J. (2014). Diagnosis and classification of Kawasaki disease. Journal of Autoimmunity, 48-49, 113-117.

SDCEP-Anticoagulants-Quick-Reference-Guide.pdf. $\quad$ (t.y.). $\quad 20 \quad$ Mayls $2020 \quad$ tarihinde http://www.sdcep.org.uk/wp-content/uploads/2015/09/SDCEP-Anticoagulants-Quick-ReferenceGuide.pdf adresinden erişildi.

Selton-Suty, C., Célard, M., Le Moing, V., Doco-Lecompte, T., Chirouze, C., Iung, B., ... Hoen, B. (2012). Preeminence of Staphylococcus aureus in Infective Endocarditis: A 1-Year Population-Based Survey. Clinical Infectious Diseases, 54(9), 1230-1239.

Singh, S., Jindal, A. K., Pilania, R. K. (2018). Diagnosis of Kawasaki disease. International Journal of Rheumatic Diseases, 21(1), 36-44.

Sosa, T., Brower, L., Divanovic, A. (2019). Diagnosis and Management of Kawasaki Disease. JAMA Pediatrics, 173(3), 278-279.

Sudo, D., Nakamura, Y. (2017). Nationwide surveys show that the incidence of recurrent Kawasaki disease in Japan has hardly changed over the last 30 years. Acta Paediatrica (Oslo, Norway: 1992), 106(5), 796800.

Tang, B., Lo, H. H., Lei, C., U, K. I., Wendy Hsiao, W-L., Guo, X., ... Law, B. Y.-K. (2020). Adjuvant herbal therapy for targeting susceptibility genes to Kawasaki disease: An overview of epidemiology, 
pathogenesis, diagnosis and pharmacological treatment of Kawasaki disease. Phytomedicine: International Journal of Phytotherapy and Phytopharmacology, 70, 153208.

Toyoda, N., Chikwe, J., Itagaki, S., Gelijns, A. C., Adams, D. H., Egorova, N. N. (2017). Trends in Infective Endocarditis in California and New York State, 1998-2013. JAMA, 317(16), 1652-1660.

Wei, Y. J., Zhao, X. L., Liu, B. M., Niu, H., Li, Q. (2016). cardiac complications in 38 cases of Kawasaki Disease with coronary artery aneurysm diagnosed by Echocardiography. Echocardiography (Mount Kisco, N.Y.), 33(5), 764-770.

Wilson, W., Taubert, K. A., Gewitz, M., Lockhart, P. B., Baddour, L. M., Levison, M., ... Newburger, J. W. (2007). Quality of care and outcomes research interdisciplinary working group. Prevention of infective endocarditis: Guidelines from the American Heart Association: a guideline from the American Heart Association Rheumatic Fever, Endocarditis, and Kawasaki Disease Committee, Council on Cardiovascular Disease in the Young, and the Council on Clinical Cardiology, Council on Cardiovascular Surgery and Anesthesia, and the Quality of Care and Outcomes Research Interdisciplinary Working Group. Circulation, 116(15), 1736-1754.

Yeung, R. S. M. (2005). Pathogenesis and treatment of Kawasaki’s disease. Current Opinion in Rheumatology, 17(5), 617-623.

Yumoto, H., Hirota, K., Hirao, K., Ninomiya, M., Murakami, K., Fujii, H.,... Miyake, Y. (2019). The pathogenic factors from oral streptococci for systemic diseases. International Journal of Molecular Sciences, 20(18).

Zhang, B., Hao, Y., Zhang, Y., Yang, N., Li, H., Liang, J. (2019). Kawasaki disease manifesting as bilateral facial nerve palsy and meningitis: A case report and literature review. The Journal of International Medical Research, 47(8), 4014-4018. 